Pak. j. sci. ind. res. Ser. A: phys. sci. 201255 (3) 142-148

\title{
Performance of Coconut Shell Particulate Filled Polyester Composites
}

\author{
Mala Ashok Kumar*a, G. Ramachandra Reddy ${ }^{b}$, A. Ramesh ${ }^{c}$, Bh. Nanjunda Reddyd, \\ K. R. Vishnu Mahesh ${ }^{\mathrm{e}}$ and P. Sanjeev Kumar ${ }^{\mathrm{f}}$ \\ ${ }^{a}$ Department of Mechanical Engineering, GATES Institute of Technology, Gooty, Anantapur (AP), India \\ ${ }^{b}$ Department of Polymer Science \& Technology, Sri Krishnadevaraya University, \\ Anantapur-515055, Andhra Pradesh, India \\ 'Department of Mechnical Engineering, GATES Institute of Technology, Gooty, Anantapur (AP), India \\ ${ }^{d}$ Department of Chemistry, Amrita School of Engg., Amrita Vishwa Vidyapeetham University, \\ Kasavanahalli, Bangalore-560 035, Karnataka, India \\ e Department of Chemistry, ACS College of Engineering, \#207, Kambipura, \\ Behind Raja Rajeswari Medical College, Mysore Road, Bangalore-74, India \\ fDepartment of Mechanical Engineering, Siddartha Educational Academy Group of Institutions, \\ Tirupathi, Andhra Pradesh, India
}

(received June 11, 2011; revised March 23, 2012; accepted May 9, 2012)

\begin{abstract}
Tensile and flexural properties of coconut shell particulate reinforced polyester resin matrix based composites were evaluated to assess the possibility of using these filler as a new eco-friendly material in engineering applications. Composites were made out of the function of coconut shell powder with different weight variations viz. 10, 15, 20, 25 and $30 \mathrm{wt} \%$, treated with 5\% $\mathrm{NaOH}$ alkali solution and these were prepared by hand lay-up process. Performance was increased gradually as filler content increased from 10 to $25 \mathrm{wt} \%$. On the other hand decline of the properties were observed when filler content was beyond $25 \mathrm{wt} \%$, heat deflection temperature (HDT) increased up to certain percentage (i.e. $25 \mathrm{wt} \%$ ) of filler in polyester above which no influence in its value was observed. The glass transition temperature ( Tg) and thermal stability was improved significantly. Scanning electron microscopy (SEM) micrographs were also studied to illustrate the particle/matrix interactions. These composites were further subjected to an evaluation of thermogravimetric, differential scanning calorimetry, and heat deflection temperature (HDT) analysis.
\end{abstract}

Keywords: coconut shell particulate, polyester, composites, mechanical properties, thermal properties, heat deflection temperature

\section{Introduction}

Coconut shell powder is made from the most versatile part of the coconut shell which is organic in nature. Since, it has good durability characteristics, high toughness, and abrasion resistance properties, it is suitable for long standing use. The shell is similar to hard woods in chemical composition although lignin content is higher and cellulose content is lower and due to natural fibres, it has low specific weight, which results in higher specific strength than glass. This benefits especially in parts designed for bending stiffness. Furthermore, it is renewable resource, the production requires little energy and carbon dioxide is used while the oxygen is given back to the environment. Coconut shell powder is producible with low investment at low cost which makes material an interesting product for low-wage countries. It is easy to manufacture and results

*Author for correspondence; E-mail: ashokkumarmala7@hotmail.com in considerable value addition and is used as filler in the manufacture of thermoset moulding powders like bakelite, synthetic resin glues or phenol formaldehyde. Mainly shell powder is used as filler and thus it is an industrial product. Powder of different particle size is required for different end uses (Sapuan and Maleque, 2005; Lai et al., 2005; Zan, 2004; Sapuan et al., 2001). Yet another favourable aspect of coconut shell powder is that it is comparatively cheaper filler and hence preferred by many end users (Rout et al., 2001a; 2001b; Calado et al., 2000; Nayak et al., 2000). It is imperative to locate suitability of this powder for other polymers. Even though, a very large quantity of work has been published on coconut coir, spathe fibre and its composites, research on this shell powder composites is scanty (Sapuan et al., 2003).

In the present research, authors studied an addition of coconut shell particulates into polyester in order to 
introduce new composites. Therefore, the present study was focused on the coconut shell powder filled polyester composites as a function of filler 10, 15, 20, 25 and $30 \mathrm{wt} \%$ on thermal and mechanical properties.

\section{Materials and Methods}

Materials and processing. Coconut shell powder employed in this study was obtained from (natural resourcing) 341 Christian Street, Oxford, CT 06478 USA (Table 1 ). The polyester resin and with $2 \%$ cobalt accelerator, catalyst 50\% methyl-ethyl-ketone-peroxide (MEKP) in 10\% DMA solution, ratio of the resin/ accelerator/catalyst/promoter: $100 / 2 / 2 / 2$ used in this study was obtained from Ciba-Geigy. The system was processed by wet hand-lay up technique for making the test specimens (ASTM, 2000).

Manufacturing process. Coconut shells were cleaned and broken manually into small pieces and then fed into pulverizer. Powder obtained from pulverizer was fed into rotor lift, coiled and passed through dresser to have required mesh size. Reject from the dresser was recycled. Efficient pulverizing and screening were critical aspects, and recovery was around 90\%. Tensile strength was studied using Instron Universal Testing Machine supplied by Instron Corporation; series-9 automated testing machine was used with across head speed of $5 \mathrm{~mm} / \mathrm{min}$. Testing samples were prepared like dumbbell shapes and these dimensions were $(100 \times 20$ $\times 3) \mathrm{mm}^{3}$ based on the ASTM D638 standards. In each case, ten samples were tested and average value tabulated. The tensile specimens were loaded in tension at a cross head speed of $5 \mathrm{~mm} / \mathrm{min}$ to determine their tensile behaviour. Authors used $50 \mathrm{KN}$ load cell for testing tensile samples. The specimen's shape is usually defined by the standard or specification being utilized, e.g., ASTM D638. Its specific shape is important to avoid a break or fracture within the area being gripped and to ensure the break will occur in the "gage length"

Table 1. Physical and chemical properties of coconut shell powder

\begin{tabular}{ll}
\hline \hline Physical parameters & Free flowing granular material \\
\hline Particle size & $80 \mu \mathrm{m}-100 \mu \mathrm{m}$ \\
Colour: & brown \\
Particle density & $1.6 \mathrm{~g} / \mathrm{cm}^{3}$ \\
Solubility in water: & Insoluble \\
Water reactive: & No \\
\hline \hline
\end{tabular}

(2 inches are frequently used) by reducing the cross sectional area or diameter of the specimen throughout the gage length. This has the effect of increasing the stress in the gage length since stress is inversely proportional to the cross sectional area under load. Flexural strength samples were also measured by using an INSTRON model 3369 Instrument. The stress induced due to the flexural load is a combination of compressive and tensile stresses. Flexural strength was tested using an Instron Universal Testing Machine with a crosshead speed of $5 \mathrm{~mm} / \mathrm{min}$. The three-point bending test system was used for all samples. In each case, ten samples were tested and the average value tabulated. The $50 \mathrm{KN}$ load cell was used for testing further the sample sizes and $(100 \times 20 \times 3) \mathrm{mm}^{3}$ was cut in accordance with ASTM D638.

Filler treatment. Coconut shell powder filler was placed in a glass tray with $5 \% \mathrm{NaOH}$ solution and further it was added to the tray and allowed to soak in the solution for about half an hour. Then it was removed from the tray and cleaned with distilled water several times to remove the excess quantity of $\mathrm{NaOH}$ sticking to the filler. Finally it was washed with distilled water and dried in a hot oven at $60^{\circ} \mathrm{C}$ for $1 \mathrm{~h}$.

Composite fabrication. The development of polymer composites (PMC) involved a few stages of work as shown in Fig. 1. Prior to mixing, filler was alkali treated with $5 \% \mathrm{NaOH}$ solution and kept in oven at a temperature of $60{ }^{\circ} \mathrm{C}$ for $24 \mathrm{~h}$ to ensure dryness. In the mixing process, matrix material was mixed with the filler material using internal mixer (Reck and Turk, 1999). Then the blended material was gone through the roll-mill to form a thin film. After that hot press was used to obtain homogenous thickness by applying pressure onto the thin film of the newly manufactured PMC. Mixture was poured over the glass mould. Brush and roller were used to impregnate composite. A glass mould with required dimensions was used for making sample on par with ASTM standards and it was coated with mould releasing agent poly vinyl alcohol (PVA) enabling easily to remove the sample. The closed mold was kept under pressure for $24 \mathrm{~h}$ at room temperature. To ensure complete curing composite samples were post cured at $70{ }^{\circ} \mathrm{C}$ for $1 \mathrm{~h}$ and the test specimens of the required size were cut out from the sheet.

Heat deflection temperature test. The heat deflection temperature is a measure of polymers resistance to distortion under the given load at elevated temperatures 
(ASTM, 2000). The deflection temperature is also known as the heat distortion temperature (HDT). It is used to determine short term resistance. It distinguishes between materials that are able to sustain light loads at high temperature and those that lose their rigidity over narrow temperature range.

The heat distortion temperature was determined by the following test procedure outlined in ASTM D638. The test specimen was loaded in three point bending in the edgewise direction. The outer fibre stress used for testing was either $0.455 \mathrm{MPa}$ or $1.82 \mathrm{MPa}$, and the temperature was increased at $2{ }^{\circ} \mathrm{C} / \mathrm{min}$ until the specimen deflected $0.25 \mathrm{~mm}$. These are associated with the determination of the HDT is that the sample is not thermally isotropic and, thick samples in particular, will contain a temperature gradient. The HDT of a particular material can also be very sensitive to stress experienced by the component which is dependent on the component's

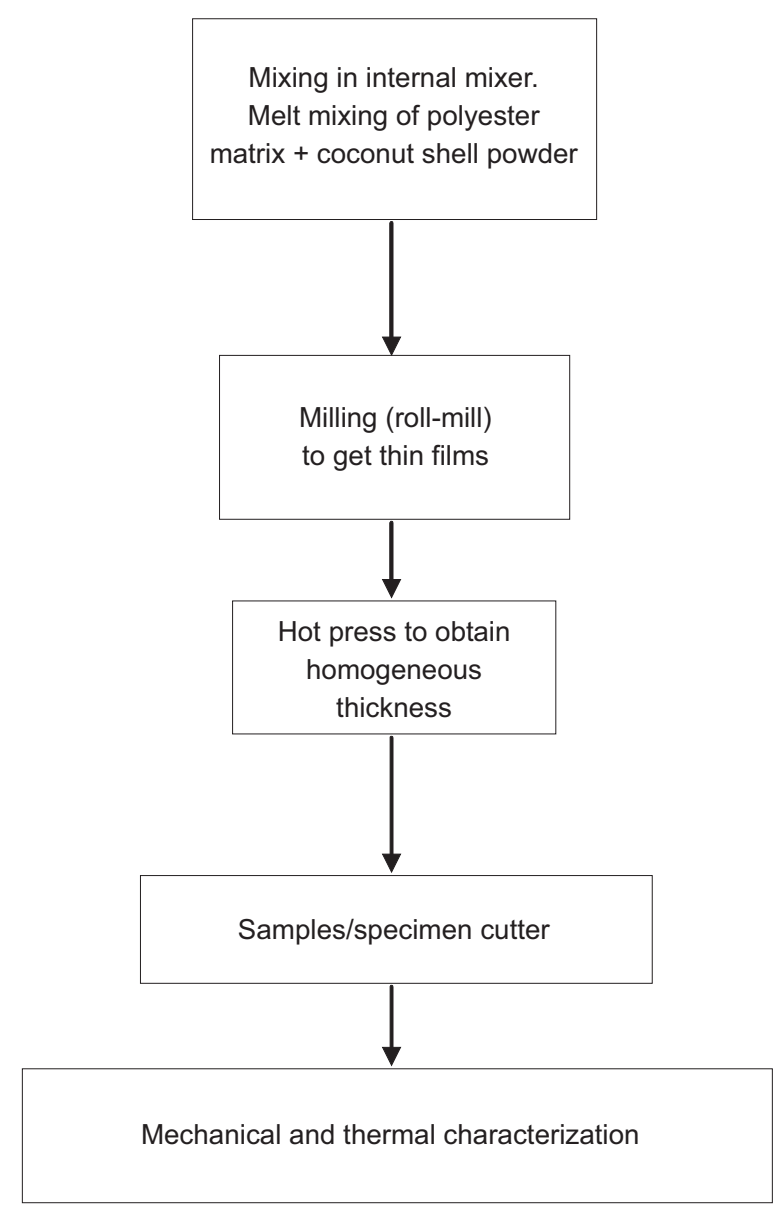

Fig. 1. Workflow for coconut shell powder filled polyester composites. dimensions. The selected deflection of $0.25 \mathrm{~mm}$ (which is $0.2 \%$ additional strain) is selected arbitrarily and has no physical meaning.

Thermal analysis. The thermal characteristics of the composites were measured using both differential scanning calorimetry (DSC-2010 TA Instrument) and thermogravimetric analyses (TGA) at a rate of $10^{\circ} \mathrm{C} / \mathrm{min}$ under nitrogen flow.

SEM analysis. Scanning electron microscopy (SEM) studies of the fractured surface of the tensile specimen were carried out on a Jeol (6380 LA, Japan). The specimen was sputter-coated with gold to increase surface conductivity.

\section{Results and Discussion}

Tensile strength verses displacement diagrams against different weight ratios are shown in Fig. 2a. It has been observed that tensile strength increased gradually when displacement varies from 0 to $0.5 \mathrm{~mm}$ for all samples such as 10,15, 20, $25 \mathrm{wt} \%$ of coconut shell filled composites, decreases when further addition of displacement from 0.5 to $0.6 \mathrm{~mm}$ for $30 \mathrm{wt} \%$ samples. Tensile strength insensitive at $30 \mathrm{wt} \%$ was due to increase in viscosity that caused agglomeration. This is evident in the increase in the critical load, with the critical load for $15 \mathrm{wt} \%$ is 0.6 times $10 \mathrm{wt} \%$, for $20 \mathrm{wt} \%$ is 0.7 times $10 \mathrm{wt} \%$, for $30 \mathrm{wt} \%$ is 0.8 times $10 \mathrm{wt} \%$ and for $25 \mathrm{wt} \%$ is 1.2 times of $10 \mathrm{wt} \%$. In other words critical load is increased up to $25 \mathrm{wt} \%$ filler where as decreased on further increase of filler. $25 \mathrm{wt} \%$ sample was optimum tensile strength when compared with other $\%$ ratios (Sapuan et al., 2003). It was observed that tensile and flexural properties of the composites increased with the increase of the filler particle content (Reck and Turk, 1999). The composite materials demonstrate somewhat linear behaviour and sharp fracture for tensile and slight non-linear behaviour and sharp fracture for flexural testing. The relation between stress and percentage of filler for tensile and flexural tests were found to be linear with correlation factors of 0.9929 and 0.9973 , respectively. Concerning the relation between the modulus and percentage of filler for tensile and flexural tests, it was found to be a quadratic relation with the same correlation factor approximated to 1 . The same behaviour was observed for the strain versus percentage of filler for tensile and flexural tests, with the same correlation factor. 
Figure $2 \mathrm{~b}$ shows the filler weight verses the ultimate tensile strength. It has been observed that ultimate tensile strength increased gradually when filler weight goes up to 10 to $25 \mathrm{wt} \%$, decreases when further increase in filler weight. Ultimate tensile strength is insensitive at $30 \mathrm{wt} \%$ due to increase in viscosity. Figure $2 \mathrm{c}$ shows the filler weight verses the normalized tensile modulus. The increase continues with the increase in weight percentages for above $25 \mathrm{wt} \%$, the properties degraded to below the $10 \mathrm{wt} \%$ is the indicative of the sensitivity of the polyester to the strength of concentration of dispersed fillers (Prasad et al., 1983).

Figure 3a shows flexural load displacement data resulting from the flexural test for five different cases for polyester filled with coconut shell powder with different variations


such as $0,10,15,20,25$ and $30 \mathrm{wt} \%$. Again a weight fraction ratio of the filler concentrations is the critical load for $15 \mathrm{wt} \%$ is 0.5 times $10 \mathrm{wt} \%$, for $20 \mathrm{wt} \%$ is 0.6 times $10 \mathrm{wt} \%$, for $30 \mathrm{wt} \%$ is 0.65 times $10 \mathrm{wt} \%$ and for $25 \mathrm{wt} \%$ is 0.9 times of $10 \mathrm{wt} \%$. Figure $3 \mathrm{a}$ also indicates that critical load for the flexural test is lesser than the tensile load and also critical load was increased up to $25 \mathrm{wt} \%$ and then dropped for further increase in filler. Figures $3 b$ and $3 c$ show the remarkable improvement in the flexural strength and flexural modulus at different concentrations of the dispersed filler. Analogues to the flexural test, results also reveal that sensitivity of the flexural properties to the concentration of the filler and performance was increased from $10 \mathrm{wt} \%$ to $25 \mathrm{wt} \%$ gradually but decreased further increase.

Thermogravimetric analysis (TGA). Figure 4 shows the weight loss verses temperature of coconut shell powder filled polyester composites. The decomposition temperature for $10 \mathrm{wt} \%$ filler was observed as $355^{\circ} \mathrm{C}$, whereas at $25 \mathrm{wt} \%$ of filler content decomposition temperature was slightly higher as $357^{\circ} \mathrm{C}$. It is clear that as the decomposition temperature of the composite shifted towards higher temperature indicating higher thermal stability of the composite due to filler loading (Van de Velde and Kiekens, 1999). Generally, the

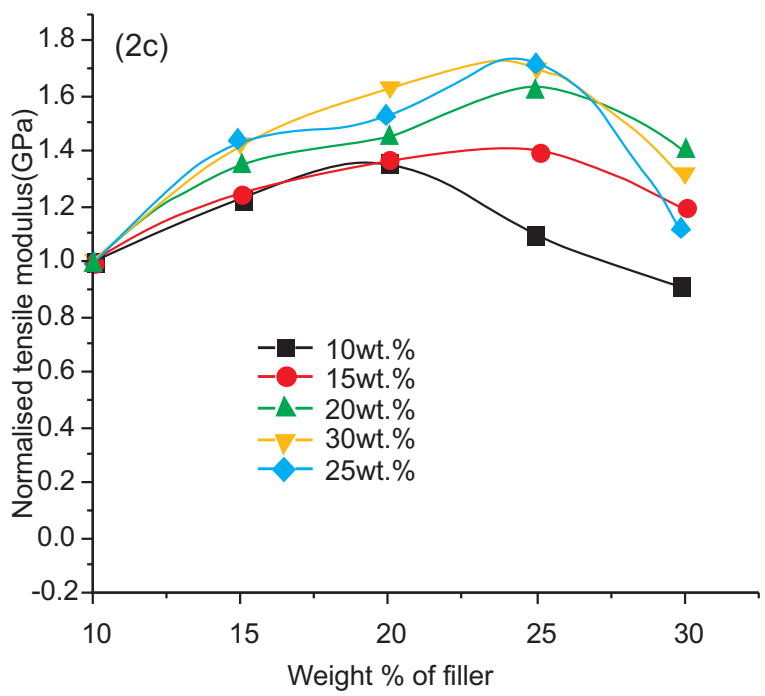

Fig. 2. Effect of filler of polyester composites of (a) tensile load verses displacement, (b) ultimate tensile strength verses weight percentage of filler and (c) ultimate tensile modulus verses weight percentage of filler diagrams on mechanical properties. 
existence of inorganic materials in polymer matrix enhances the thermal stability of the composite. Similarly in the present case, the thermal stability increased due to the presence of the inorganic phase and its interaction with the matrix. The weight loss temperature curve shows that the residue left beyond $450{ }^{\circ} \mathrm{C}$ is in line with the filler content of each sample. The result indicates that enhanced dispersion of polymer and filler increased thermal stability of the composite, as the wt \% of filler content is increased (Sapuan et al., 2001).

Differential scanning calorimetry (DSC) analysis. Thermograms for the matrix and two different variations of filler viz., 10 and $25 \mathrm{wt} \%$ filler polyester/composites are shown in Fig. 5. The glass transition temperature


( $\mathrm{T}_{\mathrm{g}}$ ) of polyester was observed as $356{ }^{\circ} \mathrm{C}$ for $10 \mathrm{wt} \%$ filler content where as $25 \mathrm{wt} \%$ filler was $358{ }^{\circ} \mathrm{C}$. An endothermic peak was observed at $400{ }^{\circ} \mathrm{C}$, for both the wt $\%$ composites. This peak was assigned to the melting point of the crystalline arms of polyester chains. Figure 6 shows the variation in heat deflection temperature of the polyester composites deflects by $0.23 \mathrm{~mm}$. It is realized that the HDT increases up 25 wt \% filler content in polyester resin material above which not much variation is observed in its value.

Fractured surface analysis. The scanning electron micrographs after tensile testing of the coconut shell powder particulate filled polyester fractured surfaces are shown in the Fig. 7a and b. In Fig. 7a the simultaneous fracture of both the filler and the matrix can be seen, suggesting a strong adhesion between them. However, no evidence of filler pull outs in the matrix was found. Uniform particle distribution seen in the figure 7a played vital role in improving bonding strength and interface was instrumental role for optimizing performance at $25 \mathrm{wt} \%$ filler. But at $30 \mathrm{wt} \%$ loading there were found some micro voids which might have occurred by poor stress transfer.

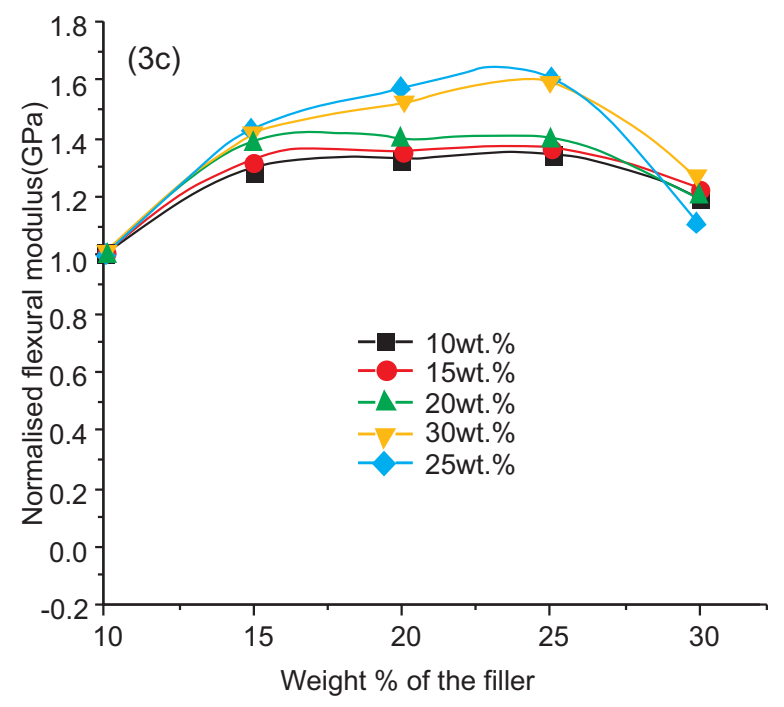

Fig. 3. Effect of Filler of polyester composites of (a) flexural load verses displacement, (b) ultimate flexural strength verses weight percentage of filler and (c) ultimate flexural modulus verses weight percentage of filler diagrams on mechanical properties. 


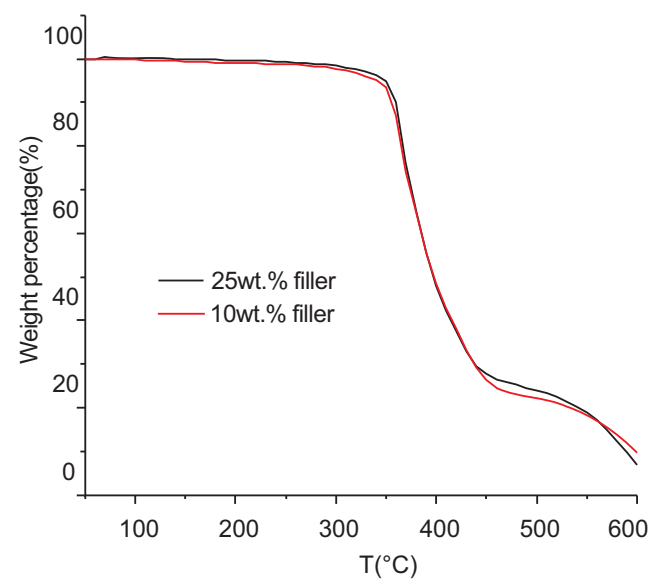

Fig. 4. TGA results of polyester composites as a function of coconut shell powder.

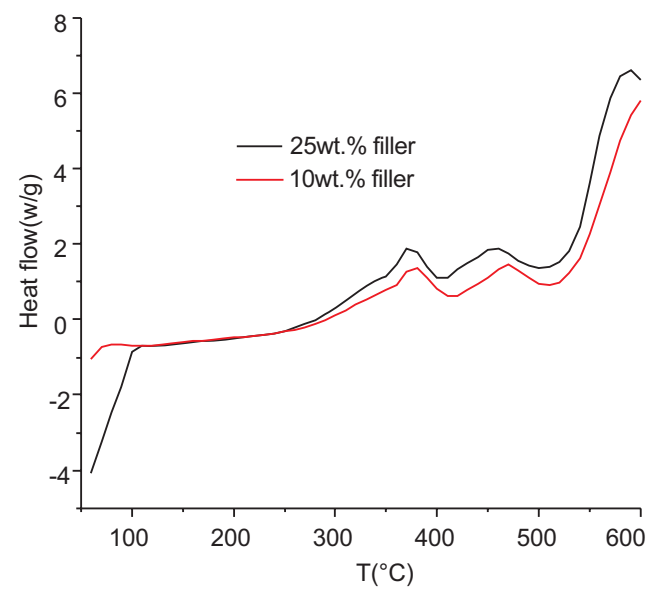

Fig. 5. DSC results of polyester composites as a function of coconut shell powder polyester bases composites.



Fig. 6. Variation of HDT as a function of coconut shell powder.

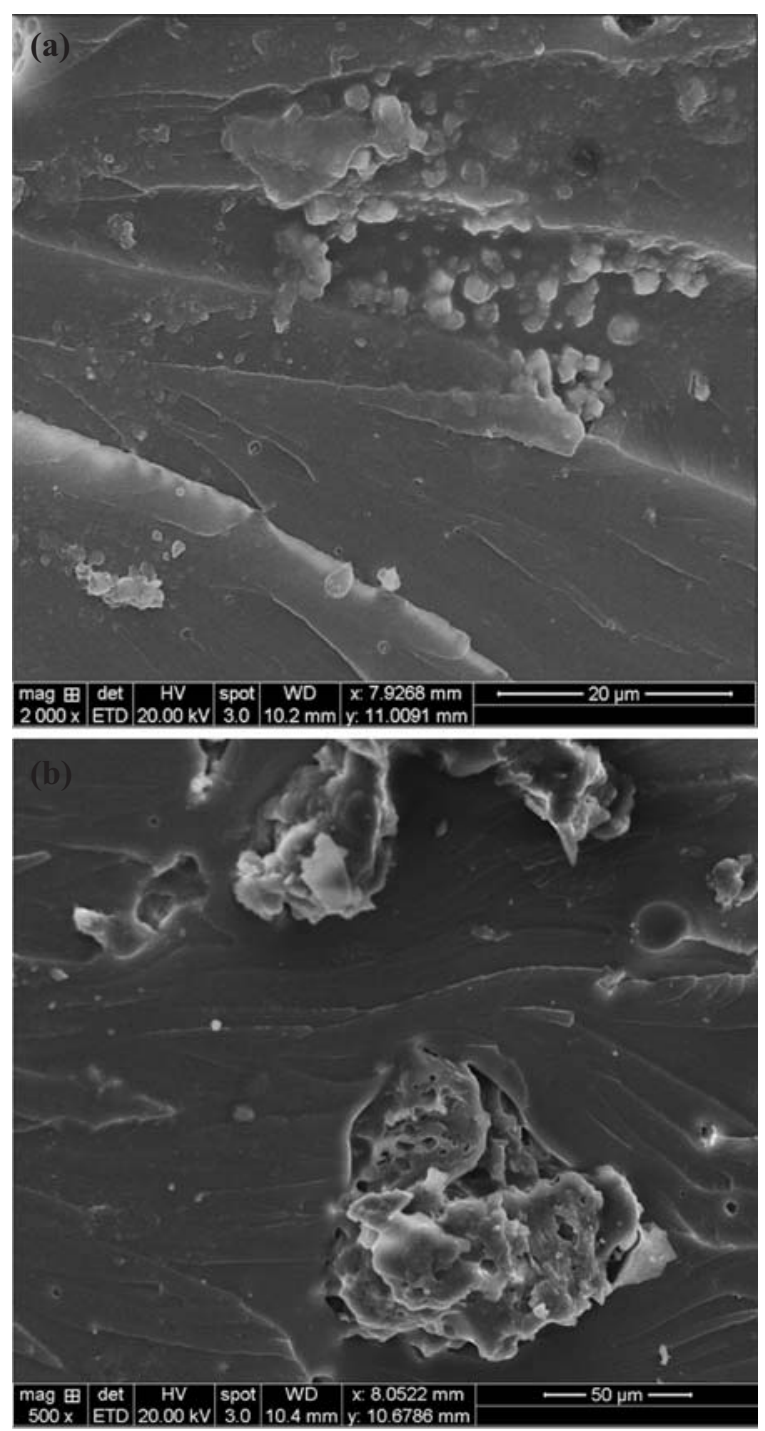

Fig. 7. SEM analysis on two different loadings of (a) $25 \mathrm{wt} \%$; (2000X) (b) $30 \mathrm{wt} \%$ (500X); of coconut shell powder particulates doped into the polyester composites.

\section{Conclusion}

The present study has focused an attention on the determination of influence of the homogenous dispersion of filler in polyester for the purpose of increasing interfacial strength. Coconut shell powder was used with different wt variations viz 10, 15, 20, 25 and 30 to evaluate the tensile and flexural properties of the filler dropped polyester composites. Authors attribute that tensile and flexural properties of filler reinforced composites increase with the incorporation of coconut shell powder into the polymer matrix due to the transfer of stress from the matrix to the fibre. However, mechanical 
properties of polymer composites showed a slight decrease with the increase filler content from $25 \mathrm{wt} \%$ to $30 \mathrm{wt} \%$ was due to the increase in viscosity off the modified composites. Increase in interface, large surface area of the filler and the consequent interlocking of the filler with the polyester were instrumental. The experimental results also shows that there is limit to the number of dispersed filler beyond which a drop in the properties is observed. Coconut shell particulates can be suitable alternative to synthetic fillers as a green filling material for the preparation of various industrially useful polymer matrix based composites.

\section{Acknowledgement}

Authors would thank to the Department of Polymer Science and and Department. of Mechanical Engg., at Sri Krishnadevaraya University, Anantapur for laboratories and instruments facilities to conduct this research.

\section{References}

ASTM, 2000. ASTM D 638-99-2000 and 790-99-2000. American Society for Testing and Materials (ASTM), pp. 1-13 and 145-151, Committee on Standards. West Conshocken, PA, USA.

Calado, V., Barreto, D.W., Dalmeida, J.R.M. 2000. The effect of a chemical treatment on the structure and morphology of coir fibres. Journal of Materials Science Letters, 19: 2151-2153.

Lai, C.Y., Sapuan, S.M., Ahmad, M., Yahya, N., Dahlan, K.Z.H.M. 2005. Mechanical and electrical properties of coconut coir fibre reinforced polypropylene composites, Polymer Plastics Technology Engineering, 44: 1-14.

Nayak, S.K., Tripahy, S.S., Rout, J., Mohanty, A.K. 2000. Coir-polyester composites: effect on fibre surface treatment on mechanical properties of composite, International Plastics Engineering and Technology, 4: 79-86.

Prasad, S.V., Pavithran, C., Rohatgi, P.K.1983. Alkali treatment of coir fibres for coir-polyester composites. Journal of Materials Science, 18: 1443-1454.

Reck, B., Turk, J. 1999. Thermally curable aqueous acrylic resins - a new class of duroplastic binder for wood and natural fibres, Macromolecular Materials and Engineering, 272: 5-10.

Rout, J., Nayak, S.S., Misra, M., Mohanthi, A.K. 2001a. Scanning electron microscopy study of chemically modified coir fibres. Journal of Applied Polymer Science, 79: 1169-1177.

Rout, J., Mishra, A., Tripanthy, S.S., Nayak, S.K., Mohanty, A.K. 2001b. The influence of fibre treatment on the performance of coir-polyester composites. Composite Science and Technology, 61: 1303-1310.

Sapuan, S.M., Maleque, M.A. 2005. Design and fabrication of natural woven fabric reinforced epoxy composite for household telephone stand, Material \& Design, 26: 65-71.

Sapuan, S.M., Harimi, M., Maleque, M.A. 2003. Mechanical properties of epoxy/coconut shell filler particle composites. Arabian Journal of Science Engineering, 28: 171-181.

Sapuan, S.M., Hassan, M.Y., Kassim, M.R. 2001. Tensile and flexural properties of epoxy composites based on coconut fibre. Cienc Tecnology Dos Materials, 13: 41-43.

Van de Velde, K., Kiekens, P. 1999. Wettability of natural fibres used as reinforcement for composites. Macromolecular Materials and Engineering, 272: 87-93.

Zan, M.N.M. 2004. Tensile and flexural properties of coconut spathe fibre reinforced composites, B.E. Thesis, 25 pp., Universiti Putra, Malaysia. 